\title{
The Telemedicine-Based Pediatric Examination of the Neck and Upper Limbs: A Narrative Review
}

\author{
Virginie Boisvert-Plante (D) ${ }^{I, *}$ \\ Constantinos Dean Noutsios (iD ${ }^{1, *}$ \\ Jordi Perez (iD) 2,3 \\ Pablo Ingelmo (iD) 3,4 \\ 'Faculty of Medicine, McGill University, \\ Montreal, QC, Canada; ${ }^{2}$ Alan Edwards \\ Pain Management Unit, Montreal General \\ Hospital (McGill University Health \\ Centre), Montreal, QC, Canada; ${ }^{3}$ Alan \\ Edwards Centre for Pain Research, \\ McGill University, Montreal, QC, Canada; \\ ${ }^{4}$ Edwards Family Interdisciplinary \\ Complex Pain Centre, Montreal \\ Children's Hospital (McGill University \\ Health Centre), Montreal, QC, Canada \\ *These authors contributed equally to \\ this work
}

\begin{abstract}
With the COVID-19 pandemic hastening the adoption of telemedicine into clinical practice, it has also prompted an abundance of new literature highlighting its capabilities and limitations. The purpose of this review is to summarize the current state of the literature on telemedicine applied in the context of a musculoskeletal examination of the neck and upper limbs for children 3 to 18 years old. The PubMed and ScienceDirect databases were searched for relevant articles from January 2015 to August 2021 using a combination of keywords and nested searches. General examination components including inspection, guided self-palpation, range of motion, sensory and motor examination, as well as special testing are described. Although the literature is focused mainly on adult populations, we describe how each component of the exam can be reliably incorporated into a virtual appointment specific to pediatric patients. Caregivers are generally needed for most consultations, but certain maneuvers can be self-performed by older children and adolescents alone. There is general feasibility, validity, and substantial reliability in performing most examination components of the upper limbs remotely, except for the shoulder exam. Compared to those made in person, clinical diagnoses established virtually were found to be either the same or similar in most cases, and management decisions also had high agreement. Despite this, there is evidence that some pediatric providers may not be able to collect all the information needed from a telemedicine visit to make a complete clinical assessment. Lastly, currently available smartphone applications measuring joint range of motion were found to have high reliability and validity. This narrative review not only establishes a foundation for a structured pediatric musculoskeletal examination, but also aims to increase physicians' confidence in incorporating telemedicine into their standard of care.
\end{abstract}

Keywords: telehealth, telemedicine, eHealth, pediatric, musculoskeletal, evaluation

\section{Introduction}

The current COVID-19 pandemic has imposed unprecedented changes in the way we conduct medical practice. Healthcare providers experienced an abrupt transition as non-urgent medical services for pediatric patients were replaced by videoconference meetings or telephone encounters, ${ }^{1,2}$ carrying their own set of advantages and limitations. $^{3}$

Telemedicine is an evolving platform broadly defined as the use of information technology to deliver healthcare services at a distance. ${ }^{4}$ While its efficacy and applicability may vary by pediatric specialty, setting, and patient preference, ${ }^{5}$ it can be used for various purposes. One important example is virtual pediatric pain clinics. A survey of Canadian pediatric pain clinics demonstrated a rapid transition to providing virtual care without any changes in the frequency of appointment requests, and with most
Correspondence: Pablo Ingelmo Email pablo.ingelmo@mcgill.ca 
patients reporting no perceived change in pain levels or occurrence of flares. ${ }^{6}$ In addition, patients from these clinics who answered the Patient Assessment of Communication During Telemedicine survey had a largely positive perception of the therapeutic relationship with their physician when compared to previous in-clinic visits, and would recommend telemedicine visits to other patients. ${ }^{7}$ Another related area in which telemedicine shows potential is virtual musculoskeletal examinations in the context of pediatric telerehabilitation medicine. $^{8}$

Videoconference-based orthopedic consultations have already been shown to be cost-effective and do not result in serious adverse events. ${ }^{9,10}$ Furthermore, telemedicine appointments have been shown to be convenient to patients and providers, leading to increased satisfaction and increased access to specialist care in rural or remote areas. $^{11,12}$ Given that musculoskeletal presentations in childhood are a common reason for primary care visits, ${ }^{13}$ a framework and standardized approach to assess and diagnose these issues via telemedicine are imperative. Not only is this of importance in the current pandemic climate but also as telemedicine continues to evolve once physical distancing restrictions are lifted.

There are several resources available to guide physicians on performing certain aspects of a pediatric telemedicine visit. These include the American Telemedicine Association's “Operating Procedures for Pediatric Telehealth"14 and the Virtual Pediatric Gait, Arms, Limbs, and Spine (V-pGALS) exam, ${ }^{15}$ the latter of which was reported to be the most commonly used standardized exam approach among pediatric rheumatologists. ${ }^{16}$ Our recent review also illustrates how to perform a virtual pediatric examination of the back and lower limbs and summarizes the advantages and limitations of performing these examinations over telemedicine. ${ }^{17}$ In addition, there are several papers describing how to perform a virtual musculoskeletal examination in adults. ${ }^{18-20}$ Despite this, there is a lack of guidelines specific to the pediatric population on how to perform a complete, virtual musculoskeletal examination with or without caregiver assistance. Furthermore, there are no other studies, to our knowledge, concurrently reviewing smartphone applications, assessment scores and the reliability/validity of performing such examinations. Therefore, the objective of this narrative review was to provide physicians with a summary of written guidelines to facilitate the physical examination of the neck and upper limbs in children 3 to 18 years old, with or without the help of a caregiver. Most of these maneuvers are based on validated physical exam techniques performed during face-to-face encounters, which have been modified to enable the child and caregiver to perform the maneuvers without requiring a clinician to be physically present. Pictures and detailed descriptions for patients and caregivers on how to perform these maneuvers can be found in the Supplemental Materials. A recent study revealed that physicians performing remote pediatric musculoskeletal examinations enlisted patient or caregiver support in $86.5 \%$ of consultations. ${ }^{16}$ While caregiver support is generally required for most visits, our own experience suggests that certain maneuvers can be self-performed by older children and adolescents alone. In addition to these guidelines, we include our own recommendations for performing certain examination components. Assessment scores amenable to the virtual platform and currently available smartphone applications for measuring joint range of motion (ROM) are equally discussed.

Lastly, the overall reliability and validity of performing individual examination components remotely is summarized, as well as their effect on diagnosis and clinical management decisions. While most studies on reliability, validity and ROM measurement included in this review use adult populations, our experience, as well as current evidence suggest that they can be applied to cooperative adolescents and older children. For instance, physical examinations performed during videoconference-based post-operative knee arthroscopy follow-ups in adolescents were found to be effective and revealed no clinically important differences when compared to in-office appointments. $^{21}$ Additionally, a smartphone inclinometer application used to measure elbow and forearm ROM demonstrated excellent validity and reliability in pediatric patients aged 6 to 15 years with elbow/forearm injuries. ${ }^{22}$ This data can increase physicians' confidence in performing examination maneuvers and when implementing smartphone tools into their practice.

\section{Methods}

The PubMed and ScienceDirect databases were searched for available journal articles from January 2015 to August 2021 published in the English language. This date range was chosen to include primarily new telemedicine technology. A research question in the population, intervention, comparison, and outcome (PICO) format was generated to guide the literature search and develop a screening process for relevant articles. The question was: "In pediatric patients with musculoskeletal pathology of the neck and 
upper limbs, are consultations delivered via telemedicine feasible and comparable to in-person appointments in terms of clinical outcomes?" The following keywords were used: telehealth, telemedicine, tele-assessment, teleconsultation, mHealth, eHealth, pediatric, adolescent, child, neck, cervical spine, shoulder, elbow, wrist, hand.

Two distinct sets of searches were performed. The first search screened for articles with the broader scope of remote physical examination in the pediatric population. The nested search used in PubMed was: ("telemedicine" [MeSH] OR "telehealth" OR "tele-assessment" OR "teleconsultation" OR "telerehabilitation" OR "eHealth" OR "mHealth") AND ("pediatric" OR "adolescent" OR "child") AND "musculoskeletal". A total of 52 citations were found from which titles and abstracts were screened for relevance and consideration for thorough review. We excluded 47 articles due to lack of relevance to our topic. Similarly, ScienceDirect was searched using the terms: ("telemedicine" OR "telehealth") AND ("pediatric" OR "child" OR "adolescent") AND "musculoskeletal". A total of 257 citations were found of which 246 were excluded. Publications on smartphone applications for ROM measurement were also screened for on PubMed and ScienceDirect using the following nested search: "smartphone" AND "range of motion". The searches yielded 626 total citations, of which 569 were excluded as they did not pertain to the joints covered in our review or lacked relevance.

Given that the first search yielded minimal pediatricspecific articles, a second search was performed to identify articles describing the physical examination of the neck, cervical spine, shoulder, elbow, wrist and hand, regardless of the patient population. The keywords mentioned previously were combined into nested searches used in
PubMed, which are described in Table 1 along with the citations the searches yielded, and the number of citations ultimately included in our review. A similar approach was used for the ScienceDirect database. Duplicates from both searches were removed, and reference lists of included citations were screened for other relevant articles, which escaped our initial search. Finally, some additional references were individually selected during manuscript preparation to provide clarification on certain topics.

\section{Neck and Cervical Spine}

Examination of the neck and cervical spine should be conducted with the camera placed at a level allowing for visualization of the head, shoulders, elbows, and hands. It is recommended that a caregiver be present to assist with camera placement, and that there be enough room for gait assessment. Patients should also be instructed to wear clothing exposing the neck and upper limbs in their entirety.

\section{Inspection and Palpation}

First, the physician can observe the neck for atrophy, fasciculations, scarring, and swelling in the coronal and sagittal planes. This involves inspection for general postural symmetry, head tilt, cervical lordosis, head-forward posture, and rounded shoulders, among others. They can then guide the patient or the caregiver to palpate the neck for tenderness as well as the spinous processes, occiput, paraspinal musculature, upper trapezius, levator scapulae and sternocleidomastoid.

\section{ROM Assessment}

The assessment of cervical spine ROM can be accomplished either by observation, or by using more

Table I Nested Searches Used in Second PubMed Iteration

\begin{tabular}{|c|c|c|c|}
\hline Section & Nested Search & $\begin{array}{l}\text { Citations } \\
\text { Yielded }\end{array}$ & $\begin{array}{l}\text { Citations } \\
\text { Included }\end{array}$ \\
\hline $\begin{array}{l}\text { Neck and } \\
\text { cervical spine }\end{array}$ & $\begin{array}{l}\text { (“telemedicine"[MeSH] OR “telehealth” OR “tele-assessment” OR “teleconsultation” OR } \\
\text { "eHealth” or "mHealth”) AND (“neck” OR “cervical spine”) }\end{array}$ & 370 & 5 \\
\hline Shoulder & 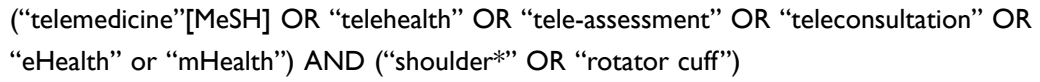 & 74 & II \\
\hline $\begin{array}{l}\text { Elbow and } \\
\text { Forearm }\end{array}$ & $\begin{array}{l}\text { ("telemedicine"[MeSH] OR “telehealth” OR “tele-assessment” OR “teleconsultation” OR } \\
\text { "eHealth” or "mHealth”) AND (“elbow*” OR “forearm”) }\end{array}$ & 26 & 4 \\
\hline $\begin{array}{l}\text { Wrist and } \\
\text { Hand }\end{array}$ & $\begin{array}{l}\text { ("telemedicine" } \mathrm{MeSH} \text { ] OR “telehealth" OR “tele-assessment" OR “teleconsultation" OR } \\
\text { "eHealth" or "mHealth") AND ("wrist*” OR "hand*” OR “finger*”) }\end{array}$ & 224 & 8 \\
\hline
\end{tabular}


quantitative methods, such as goniometry. The physician can observe for pain and limited ROM in flexion, extension, lateral flexion or rotation of the neck. In children, it can be especially effective to ask them to mirror the physician's movements on the screen. One such movement can be touching their shoulder with their ear in order to assess for lateral flexion. ${ }^{23}$ Similarly, shoulder ROM can also be assessed if there is suspicion that shoulder pathology is causing referred pain to the neck.

Obtaining quantitative measurements of cervical ROM can be facilitated using several goniometrical tools. Smartphone applications utilizing the device's inclinometer function are likely to be the easiest and cheapest tool to apply in clinical practice. However, physicians should be aware that there are no studies assessing the reliability or validity of smartphone goniometers in measuring neck ROM in pediatric populations. A summary of currently available applications and the different joint ROM they measure is found in Table 2. We identified several applications for cervical ROM that demonstrate high reliability and validity; however, a substantial proportion requires a head mount to anchor the smartphone to the patient, which may be impractical. ${ }^{24-30}$ Applications which do not require a head mount include Goniometer Pro (5fuf5; AppStore), ${ }^{31}$ Clinometer + Bubble Level (Peter Breitling, AppStore; Plaincode, Google Play), ${ }^{32,33}$ and Compass (Apple; AppStore). ${ }^{33}$ Recent studies comparing the applications to a manual goniometer and digital inclinometer found them to have good-to-excellent inter- and intra-rater reliability as well as high concurrent validity in nearly all neck movements. To use these applications in a videoconference, physicians can ask the caregiver to place the phone over different areas of the patient's head and then guide them through different neck movements. Alternatively, patients can have their ROM measured prior to a virtual visit.

Neck posture can be assessed by observation or by photogrammetry. The use of photogrammetry to quantitatively measure sagittal neck posture over telemedicine has been described in one study in which the researchers guided the patient's caregiver to place colored adhesive markers on the patient's anatomical landmarks (C7, acromion, tragus and canthus). ${ }^{34}$ These served as reference points that allowed

Table 2 Smartphone Apps and Their Studied Reliability and Validity in Measuring Joint ROM ${ }^{\mathrm{a}}$

\begin{tabular}{|c|c|c|c|}
\hline Application & Technology & Platform & Demonstrated Validity and Reliability in Joint ROM \\
\hline $\begin{array}{l}\text { Clinometer + Bubble Level (Peter Breitling; } \\
\text { Plaincode) }\end{array}$ & Inclinometer & $\begin{array}{l}\text { AppStore } \\
\text { Google } \\
\text { Play }\end{array}$ & Cervical flexion/extension, lateral flexion, rotation ${ }^{32,33}$ \\
\hline GetMyROM (Interactive Medical Productions, LLC) & Inclinometer & AppStore & $\begin{array}{l}\text { Shoulder forward flexion, abduction, internal/external } \\
\text { rotation }^{46} \\
\text { Elbow extension }{ }^{66} \\
\text { Wrist extension }\end{array}$ \\
\hline Dr. Goniometer (CDM S.r.L) & $\begin{array}{l}\text { Photo- } \\
\text { capture }\end{array}$ & AppStore & $\begin{array}{l}\text { Shoulder forward flexion, abduction, internal/external } \\
\text { rotation }^{46} \\
\text { Forearm supination }^{70}\end{array}$ \\
\hline Angle Meter* (Smart Tool Factory) & Inclinometer & $\begin{array}{l}\text { Google } \\
\text { Play }\end{array}$ & Elbow flexion/extension and forearm supination/pronation ${ }^{22}$ \\
\hline Goniometer Pro (5fuf5) & Inclinometer & AppStore & $\begin{array}{l}\text { Cervical flexion/extension, lateral flexion, rotation } \\
\text { Elbow flexion } \\
\text { W9,71 } \\
\text { Wrist flexion/extension, radial/ulnar deviation }{ }^{87}\end{array}$ \\
\hline Measure (Apple) & Inclinometer & AppStore & $\begin{array}{l}\text { Forearm supination/pronation } \\
\text { Wrist flexion/extension, radial/ulnar deviation } \\
72,73\end{array}$ \\
\hline Compass (Apple) & Compass & AppStore & $\begin{array}{l}\text { Cervical flexion/extension, lateral flexion, rotation } \\
\text { MCP, PIP, DIP joint flexion (index) } \\
8^{38}\end{array}$ \\
\hline Goniometer (June Gaming) & Inclinometer & AppStore & MCP, PIP, DIP joint flexion (index) ${ }^{88}$ \\
\hline
\end{tabular}

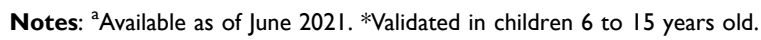

Abbreviations: ROM, range of motion; MCP, metacarpophalangeal; PIP, proximal interphalangeal; DIP, distal interphalangeal. 
the researchers to measure the sagittal head angle, craniocervical angle and shoulder angle using Microsoft Paint and an angle measurement software. ${ }^{35}$ Despite the ability of these three angles to quantitatively assess upper cervical spine extension, abnormal forward head posture and forward shoulder placement, respectively, this process was not validated in pediatric populations. Furthermore, it may prove to be difficult and time-consuming to implement in practice when compared to simple observation.

\section{Sensory Examination}

Sensory assessment can generally be performed by asking the patient to pinpoint the location of their numbness or paresthesia. Light touch sensation of the C2-T1 dermatomes can be screened independently by the patient or preferably by a caregiver using a tissue or cotton ball. ${ }^{18,36,37}$ The physician may ask the patient to keep their eyes closed to better concentrate on subtle sensory differences. If a more subtle sensory loss is suspected or if the patient's description is unclear, the physician can direct the patient or assistant to assess pinprick sensation with either a paperclip, pin, toothpick, pencil tip, or hairbrush. Temperature sensation can also be assessed with assistance from the caregiver, using an icepack or spoon that has previously been immersed in hot or cold water. Additionally, pictures of the dermatomes may be supplied to the patient and caregiver to facilitate localization.

\section{Motor Examination}

Upper extremity motor strength can be assessed either by manual muscle testing (eg, resisted biceps flexion) or by functional testing. Manual muscle testing of the upper extremity myotomes (C5-T1) can be facilitated with selfapplied resistance or resistance provided by the caregiver. If available, having the patient perform movements with a 5 to $10-1 b$ (household) weighted object can suggest at least $4 / 5$ strength and is sufficient for revealing asymmetries in strength. ${ }^{37}$ Iyer et al proposed a modified strength scale where patients are considered to have $5 / 5$ strength if they are able to perform the following: ${ }^{37}$

- Abduct the shoulder with weight $>10 \mathrm{lbs}$.

- Flex the elbow with weight $>10 \mathrm{lbs}$.

- Extend the elbow with weight $>10 \mathrm{lbs}$.

- Extend the wrist with weight $>5 \mathrm{lbs}$.

- Make a full fist with near maximal resistance from contralateral hand.
- Abduct fingers fully with near maximal resistance from contralateral hand.

Despite these useful alternatives, the physician's inability to directly provide resistance with manual testing makes it difficult to detail anything beyond $3 / 5$ strength and therefore functional testing may be more useful in the telemedicine setting. ${ }^{36}$ When assessing muscle strength via functional testing, physicians can ask the patient to perform triceps chair or wall push-ups. Younger children can be asked to put out their arms "like a boxer" for biceps strength, "chicken wings" for deltoid strength and to "push away" for triceps strength. Each position can be held for 5 seconds, evaluating for weakness. ${ }^{18}$ Observing patients as they make a fist, extend their thumb, abduct/adduct their digits, or make an "OK"/perfect sign also serves as a simple way to assess nerve function. As a final point, we urge physicians to remain cautious of their findings as strength assessment in children has been shown to be reliable in only $29 \%$ of videoconference appointments. ${ }^{16}$

It is also worth noting that no reliable method of eliciting reflexes over telemedicine has been identified, except clonus at the ankles and the Babinski reflex, ${ }^{8,18,38}$ although the latter has questionable applicability. ${ }^{37,39}$

\section{Special Testing}

Deep neck flexor endurance testing (DNFET) involves timing how long a supine patient can hold their neck flexed against gravity to the point of failure. Diminished neck flexor endurance has been associated with neck pain, cervical lordosis and headaches, and improvement in the score correlates with decreased pain and increased function. ${ }^{40}$ It has been shown to be reliable in adolescents aged 14 to 17 , and a normative data set for clinical comparison has been published for this age group. ${ }^{40}$ Although DNFET has not been studied in younger children, it has been shown to have high validity and reliability in adults when performed over telemedicine under physician guidance. ${ }^{34}$ Given DNFET's in-person reliability in adolescents and virtual reliability and validity in adults, we encourage physicians to use it confidently in adolescents aged 14 to 17 .

Physicians can screen for cervical radiculopathy by instructing the patient to perform a Spurling test without requiring the help of a caregiver. This can be done by asking them to complete a full neck extension, and then lateral bending to the right and left shoulder while using a towel to provide a downwards axial force (Figure S1). ${ }^{18,36,37} \mathrm{~A}$ positive test would recreate the patient's radicular pain or 
paresthesia in the arm. If a cervical myelopathy is suspected, the physician can ask the patient to rest their chin on their chest to reproduce Lhermitte's sign (Figure S2). Similarly, Wartenberg's sign and the grasp/release test, two special tests for cervical myelopathy, can also be easily reproduced in the telemedicine setting. Lastly, the Roos stress test can be performed to evaluate for thoracic outlet syndrome (Figure S3).

\section{Assessment Measures}

Cervical pain in children can be assessed with the Young Spine Questionnaire (YSQ) which measures prevalence and frequency of spinal problems as well as pain intensity, activity restrictions, care-seeking behaviour and influence of parental back trouble. ${ }^{41}$ Traditional neck pain and disability scores such as the Northwick Park Neck Pain Questionnaire (NPQ) and the Neck Disability Index (NDI) were designed for the working-age population and thus include sections unapplicable to children. While there is currently no evidence of a validated pediatric form of the NPQ or NDI, the YSQ has been shown to be valid and feasible for children aged 9 to 11 years.

\section{Reliability and Validity}

A survey of pediatric rheumatologists performing virtual musculoskeletal exams revealed that $62 \%$ of the cervical spine assessments were reliably performed over videoconference. ${ }^{16}$ When comparing virtual cervical spine consultations in adults to their face-to-face counterpart, a high degree of concurrent validity as well as excellent interand intra-rater reliability was observed for neck posture, active ROM, and DNFET. ${ }^{34}$ Additionally, substantial and near-perfect intra-rater reliabilities were observed for Lhermitte's sign and the Spurling test, respectively. ${ }^{42}$

\section{Shoulder}

Before initiating the consultation, patients should be instructed to wear clothing exposing the upper limbs fully from hand to shoulder, including the scapular region. An assessment of the cervical spine should be performed prior to initiating the examination of the shoulder. In a post-operative shoulder evaluation, physicians can condense the core examination to emphasize inspection of the surgical site and ROM testing.

\section{Inspection and Palpation}

With the patient facing the camera, physicians can assess the symmetry and contour of the shoulders. Similarly, scapular winging can be assessed with the patient's back towards the camera. Scars, erythema, atrophy, deformity and swelling should be assessed in both views.

Patients can then be guided to perform self-palpation beginning at the sternal notch followed by sternoclavicular joint, clavicle, acromioclavicular joint, acromion, and subacromial space noting any tenderness in these areas. The scapular spine can be palpated if ROM allows. If the patient is cooperative and can be guided to externally rotate their shoulder by $10^{\circ}$, they can self-palpate the bicipital groove with the opposite hand. ${ }^{20}$ Sufficient anatomical knowledge, palpatory skills and graded pressure are necessary to perform palpation, which may render it unsafe if the assistant palpates too intensely.

\section{ROM Assessment}

Shoulder ROM can be assessed virtually through visual estimation, web-based goniometers, digital photography or inclinometer-based smartphone applications. To assess ROM through visual inspection, the patient should face the camera when performing active abduction, and turn $90^{\circ}$ to the side for forward flexion, extension, internal and external rotation. In addition, the patient can face away from the camera when performing an Apley scratch test to assess for internal rotation. ${ }^{43}$ Abnormalities in scapular motion during abduction and forward flexion may suggest scapular dyskinesia or weakness of scapular stabilizing muscles. Physicians can demonstrate movements to patients beforehand and caregivers can assist in passive ROM testing. To facilitate this process for young children, they can be asked to reach for a toy in all planes of motion. To complement visual inspection, internet-based goniometers are available as browser extensions (eg, Protractor by Ben Burlingham) compatible with most videoconferencing applications (including Zoom, InTouch Health, and Doxy.me) when launched through the Google Chrome browser. ${ }^{20}$

Shoulder ROM can also be quantified using digital photography followed by joint angle quantification through an image manipulation software, such as Photoshop (Adobe) or ImageJ (National Institutes of Health). This method has been found to have excellent inter-rater reliability ${ }^{44}$ and is as accurate as manual goniometry and visual estimation for all shoulder motions. ${ }^{45}$

Two smartphone applications, GetMyROM (Interactive Medical Productions, LLC; AppStore) and Dr. Goniometer (CDM S.r.L; AppStore) were studied for their ability to measure shoulder abduction, forward flexion, internal and 
external rotation. Both applications require the use of an armband to position the smartphone along the humerus or forearm. While GetMyROM is an inclinometer-based app, Dr. Goniometer is photo-capture-based that allows parents to take a picture with the shoulder in the frame, and subsequently position moveable markers to calculate the angle. Overall, they were found to have good-to-excellent inter- and intra-rater reliability as well as excellent validity when compared to manual goniometry. ${ }^{46}$ Despite this, both applications were only studied in adults and photos must be taken at a specific angle to yield good results, which may present a challenge when dealing with younger children.

\section{Sensory Examination}

As described in the previous section, physicians can screen for touch, pinprick, and temperature sensation of the dermatomes supplied by the axillary, radial, medial (ante) brachial cubital and intercostobrachial nerves.

\section{Motor Examination}

Strength in internal and external rotation can be tested independently using a door frame to provide resistance, asking the patient if they feel pain or weakness. ${ }^{18}$ The subscapularis can be isolated with a belly press test, and the supraspinatus can be isolated by applying self-resistance with the other arm in a Jobe/empty can test. Alternatively, common household items of known weights, such as a grocery bag containing canned goods, or simply caregiver resistance, can be used in any of the shoulder movements. ${ }^{18,20,43,47,48}$ Scapular symmetry, strength and winging can be assessed by asking the patient to perform a wall push-up.

\section{Special Testing}

Special testing of the shoulder is described in Table 3, Figure 1A-D and Figures S4-S17. Maneuvers requiring resistance are relatively straightforward and can be facilitated by a caregiver, by holding weighted objects, or by providing self-resistance.

\section{Assessment Scores}

We identified two assessment scores that have been studied in children with shoulder pathology.

(i) Pediatric/Adolescent Shoulder Survey (PASS). This 13-question survey includes questions on pain, symptom severity, and functional limitation. It has been shown to have excellent psychometric properties, internal reliability and concurrent validity in children aged 11 to 18 years, and is not affected by sex. $^{49}$

(ii) Quick Disabilities of the Arm, Shoulder and Hand (QuickDASH). This abbreviated version contains 11 questions on the individual's symptom severity and ability to complete daily tasks, with optional modules on work, sports and performing arts. It was found to have good internal reliability and validity in patients aged 8-18 years with upper extremity injuries. ${ }^{50}$

Although neither score has been validated in the context of a remote consultation, we believe they are amenable to the virtual platform due to their availability and utilization of a Likert scale, allowing for easy administration.

In contrast, three other scores have been studied in the telemedicine context, though not in children specifically. These include the Constant score, ${ }^{51}$ Shoulder Telehealth Assessment Tool (STAT) ${ }^{52}$ and the American Shoulder and Elbow Surgeons (ASES) Standardized Shoulder Assessment Form. $^{53}$ We remind physicians that using patient-reported scores developed for adults in their pediatric patients could result in unreliable data that has limited validity or applicability.

\section{Reliability and Validity}

While there are no studies examining the reliability or validity of virtual shoulder examinations on children, we identified some in the adult population, which may increase physicians' confidence in performing a remote exam on pediatric patients. A recent case-control study on 62 adults with shoulder pain examined the validity of performing a videoconference-based physical exam facilitated by an assistant, as compared with an in-person exam for the diagnosis of rotator cuff tears. ${ }^{54}$ While ROM testing was found to have fair-to-moderate agreement, strength testing had slight agreement, and special testing overall exhibited slight-to-moderate agreement. Of the special tests, the belly press, lift-off, and HawkinsKennedy tests were found to only have slight agreement, while Neer's sign and the drop-arm test had fair agreement. Intuitively, tests that required minimal intervention by an examiner had higher agreement, such as the painful arc test. Despite this, there was no significant difference 
Table 3 Special Testing of the Shoulder via Telemedicine

\begin{tabular}{|c|c|c|}
\hline Test (Clinical Correlate) & $\begin{array}{l}\text { Assistance } \\
\text { Required? }\end{array}$ & How to Examine via Telemedicine \\
\hline $\begin{array}{l}\text { Jobe/Empty can test (supraspinatus } \\
\text { injury) }\end{array}$ & No* & $\begin{array}{l}\text { Patient is asked to hold a weighted object, such as a large soda bottle, with their arms } \\
\text { in } 90^{\circ} \text { abduction and } 40^{\circ} \text { of forward flexion with the thumbs pointing down } \\
\text { (pronation). Alternatively, a caregiver can provide resistance. Pain or weakness with } \\
\text { resistance is a positive test. }\end{array}$ \\
\hline Gerber/Lift-off test (subscapularis injury) & No* & $\begin{array}{l}\text { With their back facing the camera, patients are asked to place the dorsum of their } \\
\text { hand on their lower back in internal rotation and lift their hand away. If the patient is } \\
\text { able to do the latter, a caregiver can provide resistance against extension of the arm } \\
\text { as it lifts off the back. Pain and weakness are a positive test. }\end{array}$ \\
\hline Hornblower test (teres minor injury) & Yes & $\begin{array}{l}\text { Patient places their arm in } 90^{\circ} \text { in the scapular plane and flexes the elbow to } 90^{\circ} \text {. } \\
\text { Caregiver provides resistance against the patient's external rotation. Pain or } \\
\text { weakness is a positive test. }\end{array}$ \\
\hline $\begin{array}{l}\text { Resisted external rotation (infraspinatus } \\
\text { and teres minor injury) }\end{array}$ & No* & $\begin{array}{l}\text { Patient lies on unaffected side facing the camera so that the injured shoulder faces up. } \\
\text { With that elbow flexed at } 90^{\circ} \text { and tucked to the side, patient lifts a weighted object in } \\
\text { external rotation. Alternatively, patient sits with arms close to their side and elbow } \\
\text { flexed at } 90^{\circ} \text { and caregiver resists patient's external rotation. Pain or weakness is a } \\
\text { positive test. }\end{array}$ \\
\hline Drop arm sign (complete RC tear) & No* & $\begin{array}{l}\text { Patient is asked to abduct their arm to } 90^{\circ} \text { with the palm down, then lower that arm } \\
\text { slowly. The arm dropping to the side is a positive test. Alternatively, a caregiver can } \\
\text { be asked to passively abduct the patient's arm and let it go. }\end{array}$ \\
\hline Neer's sign (subacromial impingement) & No* & $\begin{array}{l}\text { Patient is asked to hold a weighted object and perform maximal forward flexion and } \\
\text { internal rotation of their shoulder. Alternatively, a caregiver can passively put the } \\
\text { patient's arm in forward flexion and internal rotation. Pain reproduction is a positive } \\
\text { test. }\end{array}$ \\
\hline $\begin{array}{l}\text { Hawkins-Kennedy test (subacromial } \\
\text { impingement) }\end{array}$ & No* & $\begin{array}{l}\text { Ask patient to abduct the shoulder and flex the elbow, both to } 90^{\circ} \text { and use the other } \\
\text { hand to grasp the wrist. While keeping the elbow in the same bent position, ask } \\
\text { patient to push their wrist down, while internally rotating the shoulder. }{ }^{18,47,48} \text { Repeat } \\
\text { several times. Pain is a positive test. Patient can also touch the top of their } \\
\text { nonaffected shoulder with the hand of affected side while lifting that elbow. } \\
\text { Alternatively, a caregiver can perform the original test with guidance. }\end{array}$ \\
\hline Painful arc (subacromial impingement) & No & $\begin{array}{l}\text { Patient is instructed to abduct the arm in the scapular plane and communicate when } \\
\text { they feel pain. A positive test is pain between } 60-120^{\circ} \text { which reduces past } 120^{\circ} \text {. }\end{array}$ \\
\hline $\begin{array}{l}\text { O’Brien test (AC joint pathology, glenoid } \\
\text { labrum injury) }\end{array}$ & No* & $\begin{array}{l}\text { Patient forward flexes shoulder to } 90^{\circ} \text { with full elbow extension, combined with } \\
10-15^{\circ} \text { of horizontal adduction and internal rotation. Self-resistance or caregiver } \\
\text { resistance can be applied with a downward force to the tested arm. The maneuver is } \\
\text { repeated will full forearm supination. A weighted object can also be used. }{ }^{20,47,48}\end{array}$ \\
\hline $\begin{array}{l}\text { Apley scarf (crossover) test (AC joint } \\
\text { pathology) }\end{array}$ & No* & $\begin{array}{l}\text { Patient places their arm in } 90^{\circ} \text { forward flexion and can use their other arm to adduct } \\
\text { the injured arm across their chest. Pain at AC joint with or without limitation of } \\
\text { movement is a positive test. Alternatively, a caregiver can passively perform the } \\
\text { adduction. }\end{array}$ \\
\hline Speed test (bicipital tendonitis) & No* & $\begin{array}{l}\text { While holding a weighted object, patient forward flexes their shoulder to } 60^{\circ} \text { with } \\
\text { the elbow in extension and forearm in supination. Pain in the bicipital groove is a } \\
\text { positive test. Alternatively, the patient can use resistance provided by pushing } \\
\text { upwards on a table/desk or apply self-resistance with the opposite arm. }{ }^{18} \mathrm{~A} \text { caregiver } \\
\text { can also resist the patient's flexion while palpating the bicipital groove. }\end{array}$ \\
\hline
\end{tabular}

(Continued) 
Table 3 (Continued).

\begin{tabular}{|c|c|c|}
\hline Test (Clinical Correlate) & $\begin{array}{l}\text { Assistance } \\
\text { Required? }\end{array}$ & How to Examine via Telemedicine \\
\hline Yergason test (bicipital tendonitis) & No* & $\begin{array}{l}\text { With the arm to the side and elbow flexed at } 90^{\circ} \text {, patients are to provide self- } \\
\text { resistance against supination and external rotation. Alternatively, a caregiver can } \\
\text { resist supination and external rotation. Pain or weakness in the bicipital groove is a } \\
\text { positive test. }\end{array}$ \\
\hline $\begin{array}{l}\text { Load-shift test (glenohumeral joint } \\
\text { instability) }\end{array}$ & Yes & $\begin{array}{l}\text { Patient sits with arms relaxed at sides while caregiver moves humeral head anteriorly } \\
\text { and posteriorly. Substantial movement is a positive test. }\end{array}$ \\
\hline $\begin{array}{l}\text { Anterior apprehension (anterior } \\
\text { shoulder instability) }\end{array}$ & No* & $\begin{array}{l}\text { Patient performs } 90^{\circ} \text { of shoulder abduction combined with } 90^{\circ} \text { of external rotation. } \\
\text { Apprehension with the sensation of subluxation of the humeral head is a positive test, } \\
\text { not pain. Patient can also place their elbow against a vertical surface and slightly lean } \\
\text { forward. }{ }^{76} \text { Alternatively, the patient can lie supine in the same position with the arm } \\
\text { hanging off the bed while the caregiver slowly provides an external rotation force. }\end{array}$ \\
\hline Sulcus sign (inferior shoulder instability) & Yes & $\begin{array}{l}\text { Patient sits with the arm to the side and caregiver pulls elbow downward. A gap > I } \\
\text { finger-width between lateral acromion and humeral head suggests inferior instability. }\end{array}$ \\
\hline Roos test (thoracic outlet syndrome) & No & $\begin{array}{l}\text { Instruct patient to place shoulders in } 90^{\circ} \text { abduction- external rotation and then open } \\
\text { and close fists slowly for } 3 \text { minutes. Pain in the neck, shoulder, arm with paresthesia } \\
\text { in forearm and fingers is a positive test. }\end{array}$ \\
\hline
\end{tabular}

Note: *Test can be facilitated by a caregiver.

Abbreviations: RC, rotator cuff; AC, acromioclavicular.

between the overall diagnostic accuracy of the virtual versus in-person exam for rotator cuffs tears, providing level III evidence of non-inferiority.

When compared to a traditional visit, telemedicine appointments in adults with shoulder conditions demonstrated high levels of agreement with respect to clinical diagnosis and subsequent management decisions. ${ }^{55-57}$ Clinical diagnoses were either the same or similar in $59-85 \%$ of cases, agreement in the recommended management pathway was $62-71 \%$, and agreement on the need for additional diagnostic testing (eg, pathology and radiology) was $75-100 \%$. Nonetheless, videoconference examinations of the shoulder were found to yield less physical exam information compared to a conventional appointment, took longer to complete and were associated with less satisfaction by both patient and examiner. ${ }^{57}$

Lastly, there is evidence that telehealth visits for followup after rotator cuff surgery in adults are safe and effective. After undergoing a virtual physical examination at followup, patient-reported outcome measures and pain scores were not significantly different from patients assessed through an in-person appointment. ${ }^{53,58}$ Furthermore, $96 \%$ of surgical plans established in virtual visits did not change after inperson evaluation. ${ }^{59}$ Although not validated in children, this evidence suggests that the telemedicine platform can be a reasonable follow-up model to consider for patients seeking convenient and effective care following their surgery.

\section{Elbow and Forearm}

Prior to their appointment, patients should be dressed in appropriate clothing to provide complete exposure of the elbow. They should allow for adequate room in front of their device for examination, and the camera should be positioned at the elbow level both when standing and sitting. Along with a core elbow exam and special testing, physicians may want to screen for cervical spine pathology, which may co-exist and/or refer pain to the elbow. In a post-operative elbow examination, physicians can use a condensed version of the core elbow examination with emphasis on inspection of the surgical site and ROM testing.

\section{Inspection and Palpation}

All sides of the elbow should be inspected for swelling, ecchymosis, erythema, scars, and incisions. Assessment for the "Popeye" deformity and abnormalities in the patient's resting elbow position and carrying angle should be performed. ${ }^{43,60}$ If concerned about a distal biceps or 

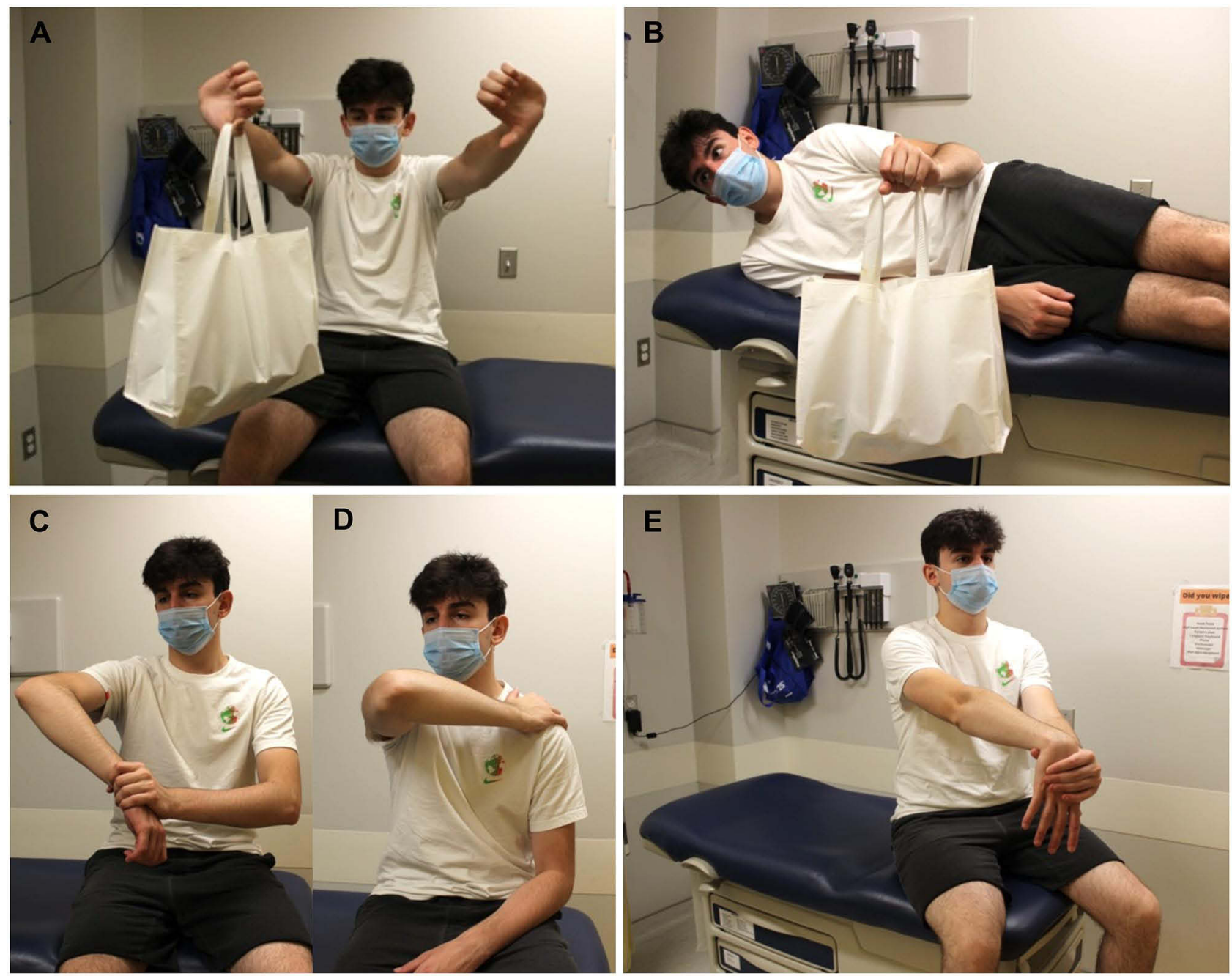

Figure I Special testing of the upper limbs | (A) Jobe/Empty can test: patient holds weighted object, such as bag with canned goods, with their arms in $90^{\circ}$ abduction and $40^{\circ}$ of forward flexion with the thumbs pointing down. (B) Resisted external rotation: in the lateral decubitus position with the elbow flexed at $90^{\circ}$ and tucked to the side, patient lifts weighted object in external rotation. Hawkins-Kennedy test: (C) with the shoulder and elbow abducted to $90^{\circ}$, patient pushes their wrist down while internally rotating that shoulder. (D) Alternatively, patient can touch the top of their unaffected shoulder with the hand of affected side while lifting that elbow. (E) Mill test: patient extends the affected arm in pronation with the wrist in flexion. Their opposite hand grips the other and pulls downward, providing resistance.

triceps injury, the symmetry of the muscle contour should be appreciated at rest, in flexion or while holding weighted items. ${ }^{20}$ Patients can then be asked to localize areas of pain and to palpate over the lateral epicondyle, medial epicondyle, and olecranon for tenderness.

\section{ROM Assessment}

While assessing for symmetry and pain, active elbow flexion and extension can be visualized with the patient turned to their side, or alternatively, facing the camera with the shoulder abducted to $90^{\circ}$. Similarly, supination and pronation can be visualized with the patient directly facing the camera with the elbows flexed. Passive ROM may be assessed by a caregiver. Additionally, physicians can employ the Beighton score to assess for generalized hypermobility, where a passive extension of the elbow greater than $10^{\circ}$ is considered hypermobile. ${ }^{61}$

Quantification of elbow ROM can be achieved using either a web-based goniometer, digital photography or inclinometer-based smartphone applications. While web-based goniometers can be used within videoconferencing applications, ${ }^{20}$ recording ROM by placing the goniometer up to the computer screen has also been shown to be comparable to in-person measurements. ${ }^{62}$ Digital photography was shown to have good validity, intra- and inter-rater reliability when measuring elbow flexion, extension, pronation and supination. ${ }^{44,63,64}$ It was also shown to have equivalent accuracy and near-equivalent precision when compared to visual 
estimation and goniometry. ${ }^{45}$ In addition, measurements based on photographs taken by patients showed no statistical difference from those taken by surgeons, ${ }^{63}$ suggesting that patients can obtain accurate photographs at home. Interestingly, smartphone mirror "selfies" were also shown to have excellent validity and intra-rater reliability when compared to manual goniometry, but patients' ability to take a usable selfie was inversely correlated with age. ${ }^{65}$

Several studies have shown that smartphone applications possess moderate-to-excellent inter-rater reliability, intra-rater reliability and validity when compared to visual estimation, manual goniometry and digital inclinometers for elbow flexion, extension, pronation and supination. ${ }^{22,66-73}$ Among the apps currently available for download are Angle Meter (Smart Tool Factory; Google Play), ${ }^{22}$ Dr. Goniometer, ${ }^{70}$ Goniometer Pro, ${ }^{69,71}$ GetMyROM, ${ }^{66}$ and Measure (Apple; AppStore). ${ }^{72,73}$ These applications either require a wrist strap, hand grip or simple positioning of the smartphone along the forearm, wrist or fingers. One such study demonstrated excellent reliability and validity using the Angle Meter app in pediatric patients aged 6 to 15 years with elbow/forearm injuries. ${ }^{22}$ Once familiar with the app, physicians can thus use Angle Meter as a valid alternative to visual inspection or goniometry for assessing elbow flexion/extension and supination/pronation in children of that age group.

\section{Sensory Examination}

As described in the Neck and Cervical Spine section, physicians can screen for touch, pinprick and temperature sensation of the dermatomes supplied by the lateral/medial antebrachial cubital nerves and radial nerve. Cubital tunnel syndrome, posterior interosseous nerve syndrome, and pronator teres syndrome can all be screened for using the special tests described in Table 4.

\section{Motor Examination}

Strength testing of the elbow can be performed against gravity, against caregiver-applied resistance, and while holding common household items such as canned goods or fluid-filled containers. ${ }^{43,60}$ Pain localizing to the medial epicondyle with wrist extension and supination while holding a weighted object is suggestive of medial epicondylitis. Similarly, pain localizing to the lateral epicondyle with wrist flexion and pronation suggests lateral epicondylitis.

\section{Special Testing}

Although the most common pediatric elbow injuries are fractures,${ }^{74}$ medial and lateral epicondylitis are frequent in children who are baseball pitchers and who play racket sports, respectively. Panner disease and osteochondritis dissecans are common in children who engage in sports involving overhead throwing or weight-bearing on their arms, such as football and gymnastics. In toddlers, subluxation of the radial head can occur when a parent grabs the arm of a falling child or when the child is pulled by the hand. Given the high prevalence of elbow pathology in active children, ${ }^{75}$ condition-specific examination over telemedicine is mandated. Efforts have been made to adapt several special tests of the elbow for videoconference consultations. ${ }^{19,20,60,76}$ They include tests for instability, valgus extension overload, tendinopathy, and nerve entrapment syndromes. The most notable tests of the elbow and forearm are presented in Table 4, Figures 1E and S18-S27, nearly all of which can be performed without a caregiver's assistance. In the context of cubital tunnel syndrome, the Tinel test has been suggested to have poor feasibility, while the elbow flexion test has good feasibility and can serve as a viable alternative. ${ }^{77}$ Modified tests for medial and lateral epicondylitis were also shown to have good feasibility.

\section{Reliability and Validity}

A study of pediatric rheumatologists performing video consultations of the elbows, wrists, and hands concluded that $63 \%$ of assessments were reliably executed. ${ }^{16}$ In adults, one study investigating remote consultations for elbow pathologies compared conventional face-to-face physical findings (including ROM, self-palpation, strength, neural tension and special testing) and pathoanatomical diagnoses to those obtained through videoconference appointments. ${ }^{55}$ It showed that $73 \%$ of the diagnoses were either similar or identical. In addition, ROM, strength, and special testing demonstrated high levels of agreement (68-98\%) except for neural tension tests and joint palpation. The poor agreement in neural tension testing was attributed to the difficulty in explaining to a naïve patient how to perform them as well, having to perform them actively rather than passively, as is conventionally done by the examiner in-office. Joint self-palpation also exhibited poor agreement due to some examiners' inability to determine if the patient was palpating the correct anatomical landmarks. Given that current evidence on the topic is limited, especially in pediatric populations, we suggest that 
Table 4 Special Testing of the Elbow and Forearm via Telemedicine

\begin{tabular}{|c|c|c|}
\hline Test (Clinical Correlate) & $\begin{array}{l}\text { Assistance } \\
\text { Required? }\end{array}$ & How to Examine via Telemedicine \\
\hline $\begin{array}{l}\text { Chair push-up test (posterolateral } \\
\text { rotatory instability) }\end{array}$ & No & $\begin{array}{l}\text { Patient is seated and instructed to push off from a chair with the forearms in supination. } \\
\text { Pain or apprehension suggests instability. }\end{array}$ \\
\hline Mill test (lateral epicondylitis) & No* & $\begin{array}{l}\text { Patient extends the affected arm in pronation with the wrist in flexion. Their opposite } \\
\text { hand grips the other and pulls downward, providing resistance. Pain in the lateral } \\
\text { epicondyle or on palpation is a positive test. If present, caregiver can provide resistance. }\end{array}$ \\
\hline Cozen test (lateral epicondylitis) & No* & $\begin{array}{l}\text { With the patient's forearm and palm flat on a table, they are instructed to make a fist, } \\
\text { radially deviate and extend the wrist while providing resistance against extension with the } \\
\text { contralateral hand } .^{77} \text { Pain in the lateral epicondyle or on palpation is a positive test. If } \\
\text { present, caregiver can provide resistance. }\end{array}$ \\
\hline Maudsley test (lateral epicondylitis) & No* & $\begin{array}{l}\text { With the patient's forearm flat on a table and in pronation, they are asked to provide self- } \\
\text { resistance against ipsilateral } 3 r d \text { digit extension. Pain in the lateral epicondyle or on } \\
\text { palpation is a positive test. If present, caregiver can provide resistance. }\end{array}$ \\
\hline $\begin{array}{l}\text { Reverse Mill test (medial } \\
\text { epicondylitis) }\end{array}$ & No* & $\begin{array}{l}\text { Patient extends the affected arm in supination with the wrist in extension. Their opposite } \\
\text { hand grips the other and pulls back, providing resistance. Pain in the medial epicondyle or } \\
\text { on palpation is a positive test. If present, caregiver can provide resistance. }\end{array}$ \\
\hline $\begin{array}{l}\text { Hook test (distal biceps tendon } \\
\text { rupture) }\end{array}$ & No & $\begin{array}{l}\text { With the unaffected elbow in flexion, patient is asked to "hook" its biceps tendon with } \\
\text { their index finger and compare this to the contralateral side. Inability to hook the tendon } \\
\text { is a positive test. }\end{array}$ \\
\hline $\begin{array}{l}\text { Tinel sign over the ulnar groove } \\
\text { (cubital tunnel syndrome) }\end{array}$ & No* & $\begin{array}{l}\text { Physician can direct patients (or caregivers) to locate then tap on the ulnar nerve at the } \\
\text { elbow. A tingling sensation in the ulnar distribution of the forearm and hand is a positive } \\
\text { sign. }\end{array}$ \\
\hline $\begin{array}{l}\text { Elbow flexion test (cubital tunnel } \\
\text { syndrome) }\end{array}$ & No & $\begin{array}{l}\text { Patient is asked to touch their shoulder with the fingertips of the ipsilateral hand and } \\
\text { hold this position for I minute. A tingling sensation in the ulnar distribution of the } \\
\text { forearm and hand is a positive sign. }\end{array}$ \\
\hline Resisted supination (PIN syndrome) & No* & $\begin{array}{l}\text { Patient is asked to rest the forearm on the armrest of a chair with the wrist hanging off } \\
\text { the edge. While holding a weighted object or weighted bags, they are asked to supinate } \\
\text { the forearm. }{ }^{60} \text { Reproduction of symptoms is a positive test. Alternatively, a caregiver can } \\
\text { provide resisted supination. }\end{array}$ \\
\hline $\begin{array}{l}\text { Resisted pronation (pronator teres } \\
\text { syndrome) }\end{array}$ & Yes & $\begin{array}{l}\text { Caregiver is asked to provide resistance against patient's pronation while extending the } \\
\text { patient's elbow. Reproduction of pain or discomfort is a positive test. }\end{array}$ \\
\hline
\end{tabular}

Note: *Test can be facilitated by a caregiver.

Abbreviation: PIN, posterior interosseous nerve.

physicians remain cautious when examining children's elbows and forearms remotely.

\section{Wrist and Hand}

Patients should be examined with their hands resting on a table and the camera focused on them from above. Alternatively, patients can hold their hands up in front of the camera. If handheld devices are the only option available, they can be secured in a steady position or held by a caregiver during the appointment. Prior to performing their examination, physicians may want to screen for cervical spine and elbow pathology as they may cause referred pain to the hand. Overall, inspection can be accomplished over telemedicine with minimal limitation, as are most aspects of the motor examination aside from strength against resistance. ${ }^{77}$ Palpation can be substituted with guided self-palpation but peripheral pulses, temperature and a formal sensory examination with two-point discrimination cannot be conducted remotely. ${ }^{77,78}$ Lastly, certain special tests can be performed consistently when incorporating the modifications highlighted below. 


\section{Inspection and Palpation}

Inspection begins with the dorsal and volar aspects of the hand and wrist by having the patient hold their hands up to the camera and perform full pronation and supination. Physicians should observe for erythema, ecchymosis, atrophy, swelling, deformities, contracture, and visible signs of arthritis or trauma while comparing to the contralateral side. Despite not being able to properly assess peripheral pulses and temperature, physicians can assess for abnormalities in the colour of the hands or have patients perform a capillary refill test with the fingernail near the camera. Visualization of the digital cascade should be performed by asking the patient to make a series of fists through flexion and extension of the digits, paying close attention to deficits in ROM or malrotation. Physicians can also expand their inspection to the forearm, elbow and upper arm as well as the nail complex. Patients can be asked to localize areas of numbness or paresthesia and then be guided to self-palpate anatomical landmarks for tenderness. This can be facilitated by a graphical depiction of relevant surface anatomy provided by the physician prior to the exam. Areas include, among others, the carpometacarpal (CMC), metacarpophalangeal (MCP), proximal interphalangeal (PIP), and distal interphalangeal (DIP) joints. Tenderness on palpation of the A1 pulley can suggest a diagnosis of the trigger finger, although guiding the patient to this landmark has poor feasibility. ${ }^{77}$ Previous injury with tenderness reported on palpation of the anatomical snuffbox warrants further investigation for a scaphoid fracture.

\section{ROM Assessment}

Using the contralateral hand, the patient is asked to first demonstrate passive ROM for end-range flexion and extension in all digits and both wrists. Caregivers can assist in this process. Active ROM of the wrist can be evaluated with the patient turned 90 degrees to the side for flexion/extension and facing the camera for radial/ulnar deviation. Younger children can be instructed to place their hands in a prayer position to assess for wrist extension. ${ }^{8}$ Active ROM of the hand can be assessed by visualizing the digital cascade followed by thumb opposition and abduction/ adduction of the digits. In addition, self-assessment of the 1st and 5th MCP hypermobility using the Beighton score can be easily performed by patients.

Physicians can use digital/smartphone photography to quantify hand and wrist ROM. This method was shown to have excellent inter- and intra-rater reliability as well as substantial to near-perfect agreement with manual goniometry and visual inspection for wrist flexion, extension, radial and ulnar deviation in adults. ${ }^{44,79-81}$ Despite this, one study found that self-taken photographs of the wrist had lower intra-rater reliability than visual estimation alone. ${ }^{82}$ For finger ROM, three studies in adults demonstrated that smartphone photography had excellent interand intra-rater reliability for MCP, PIP and DIP joint flexion and extension measurements. ${ }^{83-85}$ However, only two of the three studies demonstrated high validity when compared to manual goniometry. In addition, there were no statistical differences between photo measurements of the wrist and fingers taken by patients' family members when compared to those obtained by specialist physicians. ${ }^{79,81,83}$ When patients were provided with an illustrated instruction sheet, as low as $5 \%$ of the digital photographs were missing or deemed inadequate for measurements. ${ }^{80}$ Given the above, we suggest that patients' and their families' selftaken photographs may be valid and reliable in measuring wrist and finger ROM when presented with adequate instructions beforehand. Nonetheless, physicians should remain cautious of its applicability, especially when assessing the digits, and weigh its convenience against a simpler method such as visual inspection.

Several apps for measuring wrist ROM were identified and found to have moderate-to-excellent inter- and intrarater reliability as well as excellent validity when compared to a digital inclinometer and manual goniometer for all wrist movements. ${ }^{66,72,73,86,87}$ Among the apps currently available were Goniometer Pro, GetMyROM, and Measure. All of these require users to place the smartphone over the dorsal and volar aspects of the hand, with or without the use of a strap, while active and passive ROM are measured. Similarly, two currently available apps have been identified for measuring finger ROM: Goniometer (June Gaming; AppStore) and Compass (Apple; AppStore). ${ }^{88}$ Both have excellent inter-rater reliability and good validity when compared to radiographic measurements and manual goniometry for MCP, PIP and DIP joint flexion. Despite this, physicians found them to not to be very user-friendly relative to simple visual inspection.

\section{Sensory Examination}

Light touch sensation can be assessed by instructing the patient to place a soft object, such as a tissue, along the palm of the hand and each digit. A paperclip can help assess for pinprick sensation along the volar aspect of the 
pinky finger, index finger and first dorsal webspace to evaluate the ulnar, median and superficial radial nerves, respectively. Although a formal assessment of two-point discrimination was suggested not to be feasible, ${ }^{77}$ physicians can attempt it through the use of a paperclip with the sharp tips bent closer and closer together. ${ }^{89,90}$ Providing a graphical depiction of relevant sensory distributions can aid the patient in subjectively comparing sensation between both hands.

\section{Motor Examination}

Physicians can assess the active motor function of the extrinsic flexor and extensor muscles of the hand by having the patient block movement at certain joints in order to isolate the muscle group of interest. For example, the flexor pollicis longus can be isolated by having the patient block the MCP joint of the thumb and flex through the interphalangeal joint. The intrinsic muscles of the hand can be assessed next, paying attention to a possible Wartenberg's sign. Each maneuver should be demonstrated beforehand to help patients reliably reproduce the movements. Strength testing of wrist flexion/extension, digit extension/flexion, digit abduction and thumb abduction can be performed with resistance provided by a caregiver. Physicians can also ask patients to hold a full water bottle for resisted wrist ROM, supination/pronation and squeezing of the hand, with the bottle deforming. ${ }^{91}$ A simple nerve exam can be conducted by asking the patient to make a "thumbs up", "OK"/perfect sign and abduct the digits, evaluating the branches of the radial, medial and ulnar nerves, respectively. Lastly, physicians can perform a functional assessment by observing handwriting, thumb opposition, pinch strength (eg, lifting a load, opening water bottle, or opening a resealable bag), cylindrical grasp strength (eg, opening a jar) and spherical grasp strength (eg, squeezing a tennis ball). ${ }^{90,91}$

\section{Special Testing}

Special tests of the wrist and hand are summarized in Table 5 and in Figures S28-S36, all of which can be performed independently with prior demonstration by the physician. Given that hand injuries peak in toddlers and teenagers, ${ }^{92}$ pathology-specific testing of the hand is warranted based on the patient's history and physical examination. Tests suggested to be reliably performed over telemedicine include the Phalen and reverse Phalen tests, Wartenberg sign, as well as modified versions of the Finkelstein, Froment and triangular fibrocartilage complex
(TFCC) load tests. ${ }^{77}$ If there is suspicion of juvenile idiopathic arthritis affecting the hands, physicians can ask patients to twist open the lid of an unopened jar or try pinching a piece of paper between the thumb and second digit, and then attempt to remove it with the opposite hand. ${ }^{76}$ Pain at the base of the thumb with both these maneuvers is suggestive of first CMC joint arthritis. Lastly, self-assessment of 1st MCP hypermobility can be easily performed by patients, and a positive finding along with other signs can pinpoint towards systemic hypermobility disorders. While fractures represent one fifth of hand injuries in children, ${ }^{93}$ skier's thumb, trigger finger, and ulnar nerve injury from an associated elbow fracture are less common but should be assessed for nonetheless. ${ }^{75,94}$

\section{Reliability and Validity}

When compared to in-person examination, virtual inspection of the hands, specifically evaluating the quality of scars and incision sites after recent surgery, were found to have near-perfect agreement in two of the three studies we identified. ${ }^{95,96}$ The odd study reported that less than half of scars were noted on inspection over telemedicine, but this was without prior history taking and had no effect on subsequent clinical diagnoses. ${ }^{91}$ Furthermore, older scars are harder to identify, and without formal palpation, adequate assessment of skin moisture, turgor and heat are lacking. This can be remedied through active inquiry when inspecting the hands, higher camera resolution and good room lighting. Patient-reported localization of pain and altered sensation were found to have near-perfect agreement over videoconference when compared to in-person appointments. ${ }^{91,96}$ Visual assessment of wrist and finger ROM was found to have good-to-excellent inter- and intrarater reliability and near-perfect agreement with in-person goniometry and inspection. ${ }^{91,95-97}$ Given that experience level may impact the reliability of these measurements, we suggest that all ROM assessments be conducted by the same examiner. ${ }^{97}$ Performing a virtual motor examination including wrist flexion/extension strength as well as grip/pinch/ squeeze strength was shown to be in good agreement with in-person assessments. ${ }^{91,96}$ Special testing (observation of contracture, finger triggering and A1 pulley tenderness, recognizing subcapital metacarpal and scaphoid fractures as well as a positive Finkelstein test) demonstrated good agreement with in-person assessments. ${ }^{91}$ Lastly, in a study of 18 adults with hand pathologies who underwent a virtual physical examination, there was perfect agreement with 
Table 5 Special Testing of the Wrist and Hand via Telemedicine

\begin{tabular}{|c|c|}
\hline Test (Clinical Correlate) & How to Examine via Telemedicine \\
\hline Phalen test (carpal tunnel syndrome) & $\begin{array}{l}\text { Patient is instructed to place the dorsum of both hands against each other in forced flexion } \\
\text { and hold this position for } 30-60 \text { seconds. Presence of paresthesia in the median nerve } \\
\text { distribution is a positive test. }\end{array}$ \\
\hline Reverse Phalen test (carpal tunnel syndrome) & $\begin{array}{l}\text { Patient is instructed to place both palms against each other as in a prayer and hold this } \\
\text { position for } 30-60 \text { seconds. Presence of paresthesia in the median nerve distribution is a } \\
\text { positive test. }\end{array}$ \\
\hline Tinel sign at the wrist (carpal tunnel syndrome) & $\begin{array}{l}\text { Patient (or caregiver) is instructed to gently tap along the base of the palm over the distal } \\
\text { palmar crease where a positive test is reproduction of paresthesia in the median nerve } \\
\text { distribution. }\end{array}$ \\
\hline Finkelstein test (de Quervain's tenosynovitis) & $\begin{array}{l}\text { Patient places wrist at edge of table with ulnar aspect of hand hanging off the edge. They are } \\
\text { asked to actively ulnar deviate their wrist. If there is no pain aggravation at tip of radial styloid } \\
\text { process, patient can use the contralateral hand to provide an ulnar deviation force. If there } \\
\text { still is no pain provocation, patients can use the contralateral hand to flex the thumb into the } \\
\text { palm, assessing for pain along the tip of the styloid process. }\end{array}$ \\
\hline $\begin{array}{l}\text { Wartenberg sign (ulnar nerve palsy, cervical } \\
\text { myelopathy) }\end{array}$ & $\begin{array}{l}\text { Patient is asked to hold all fingers in adduction while fully extending them. The small finger } \\
\text { drifting into abduction indicates a positive test. }\end{array}$ \\
\hline Froment sign (ulnar nerve palsy) & $\begin{array}{l}\text { Patient grasps piece of paper between thumb and index finger on affected side and attempts } \\
\text { to pull it out with the opposite hand. Difficulty holding the paper or compensation by flexing } \\
\text { interphalangeal joint of thumb is a positive test. }\end{array}$ \\
\hline TFCC load test (TFCC tear) & $\begin{array}{l}\text { With the affected wrist in ulnar deviation, patient is instructed to apply a force across the ulna } \\
\text { with the contralateral hand, furthering the ulnar deviation. Pain is a positive test. }\end{array}$ \\
\hline Press test (TFCC tear) & $\begin{array}{l}\text { Seated patient pushes their body weight up off of a chair using the wrists. Focal ulnar wrist } \\
\text { pain is a positive test. }{ }^{102}\end{array}$ \\
\hline $\begin{array}{l}\text { Thumb MCP joint stress test (ulnar collateral } \\
\text { ligament rupture/“skier's thumb”) }\end{array}$ & $\begin{array}{l}\text { Patients should be asked to use their opposite hand to radially deviate the affected thumb } \\
\text { from the MCP joint. Physician observes for either increase in angulation in the case of a } \\
\text { complete tear, or laxity in the joint in the case of a partial tear. }\end{array}$ \\
\hline Triggering of finger & $\begin{array}{l}\text { Patients can be asked to grab and release the large handle of a mug or other similar object } \\
\text { with digits } 2-5 .^{76} \text { Subsequent extension with pain and triggering of a digit after removing the } \\
\text { fingers form the handle may be suggestive of trigger finger. }\end{array}$ \\
\hline Ist CMC grind test (carpometacarpal OA) & $\begin{array}{l}\text { Patient grips the metacarpal bone of their affected thumb and moves it in a circle, loading it } \\
\text { with gentle axial forces. Pain with possible crepitus is a positive test. }\end{array}$ \\
\hline
\end{tabular}

Abbreviations: TFCC, triangular fibrocartilage complex; MCP, metacarpophalangeal; CMC, carpometacarpal; OA, osteoarthritis.

regard to the overall clinical management decisions. ${ }^{96}$ Moreover, pediatric rheumatologists performing video examinations of the hands, wrists, and elbows found that $63 \%$ of assessments were reliably executed. ${ }^{16}$

\section{Discussion}

Adult studies have shown that there is general feasibility, validity, and substantial reliability in performing most components of the upper limbs' examination remotely except for the shoulder exam. Clinical diagnoses established virtually were found to be either the same or similar to those made in-person in the majority of cases, and management decisions had high agreement. Despite this, some pediatric providers felt that they were unable to gather the necessary information to formulate a complete clinical assessment. ${ }^{6,16}$ This may suggest a discrepancy between the reliability of virtual examinations in the context of a research study and in real-world clinical practice, especially in the setting of a pediatric virtual visit. We emphasize that pediatric musculoskeletal examinations require creativity depending on the location of the family and patient, knowledge of how to navigate technical 
issues, consideration of the examination sequence, and of how to cue the child to gain optimal views of the areas of interest, all of which are added challenges providers must consider. Concurrently, there is general agreement among pediatric specialists that routine follow-up visits, request for bloodwork, and patient concern for worsening condition can be performed reliably over telemedicine; meanwhile, agreement is divided for new patient consultations and follow-ups due to flares. ${ }^{16}$

Given the above, we recommend that physicians maintain a low threshold for undertaking further in-person evaluation. Providers can also screen new patient referrals and automatically direct the most urgent cases to a dedicated clinic. Most new and established patients can then be scheduled for a videoconference or phone appointment. This triaging process at a dedicated pediatric neurologic clinic has been demonstrated to be effective in transitioning to virtual patient care, ${ }^{1}$ and may reduce the burnout physicians may feel from handling emergent cases remotely.

Lastly, virtual consultations can be complemented with pediatric assessment scores and smartphone applications as clinicians see fit. The latter have been shown to reliably measure joint ROM in adults and can potentially be applied in adolescents and older children as well. We envision that this smartphone technology, in conjunction with assessment scores, can serve as a low-cost, feasible option for remotely monitoring patients. For instance, post-operative patients can measure their ROM prior to follow-up visits, serving as a tool in evaluating their progress and the possible need for further intervention. Despite the demonstrated reliability and validity of these applications, we urge physicians to remain cautious when interpreting results as they were studied within controlled clinical settings. Furthermore, the same reliability and validity cannot be assumed for patients and caregivers who are not familiar with using the applications. However, there is sufficient evidence that, with a standardized technique and clear instructions, the reliability of ROM measurements can be improved in untrained examiners. $^{98}$

Pediatric telemedicine provides many advantages such as increased access to healthcare as well as increased patient and caregiver satisfaction due to perceived convenience, timesaving and cost-saving. ${ }^{11,12}$ Nonetheless, there are limitations that should not be overlooked. There is, for instance, some evidence that virtual consultations may increase physicians' level of burnout and decrease patient engagement and confidentiality. ${ }^{16}$ In addition to provider reluctance in integrating telemedicine into their practice, ${ }^{99}$ it could increase disparity in healthcare delivery to rural and minority groups who lack access to such technology. ${ }^{1,100,101}$ Keeping these limitations in mind, physicians must be willing to adapt their practice to ensure patient safety and well-being.

\section{Conclusion}

Telemedicine for musculoskeletal pathology in pediatric patients presents an opportunity to deliver timely patient and family-centred care while minimizing potential exposure to COVID-19. Our review provides clinicians with foundational guidelines for performing a virtual musculoskeletal examination of the neck, cervical spine, and upper limbs, serving as a starting point for integrating the remote exam into clinical practice. It also highlighted pediatric assessment scores as well as currently available smartphone applications for their reliability in measuring joint ROM, serving as tools that clinicians can adopt into their practice.

Adult studies have demonstrated that there is general feasibility, validity, and substantial reliability in performing most components of the virtual examination. Given that some pediatric specialists felt that they were unable to gather the necessary information to formulate a complete clinical assessment of their patients, we recommend retaining a low threshold for undertaking further in-person evaluation is the diagnosis or management plan remains unclear. Future research should therefore be dedicated to validating musculoskeletal examinations in children, identifying barriers in conducting such examinations thoroughly, and training physicians on providing virtual care. Upon setting a triaging system to identify patients appropriate for remote consultations and those for in-person visits, a well-structured telemedicine consultation provides many advantages to patients, families, and clinicians. Overall, with clinician acceptance and caregiver cooperation, telemedicine is a reliable and effective tool which can be integrated into our standard of care for pediatric patients and their families.

\section{Abbreviations}

V-pGALS, virtual pediatric gait arms limbs spine; ROM, range of motion; PICO, population intervention comparison outcome; DNFET, deep neck flexor endurance testing; YSQ, Young Spine Questionnaire; NPQ, Northwick Park Questionnaire; NDI, neck disability index; PASS, 
pediatric/adolescent shoulder survey; QuickDASH, quick disabilities of the arm, shoulder and hand; STAT, shoulder telehealth assessment tool; ASES, American Shoulder and Elbow Surgeons; CMC, carpometacarpal; MCP, metacarpophalangeal; PIP, proximal interphalangeal; DIP, distal interphalangeal; TFCC, triangular fibrocartilage complex.

\section{Ethics Statement}

Informed consent has been provided by all parties, including parents or legal guardians of any minors, for their photographs to be published in this review.

\section{Acknowledgments}

The research activities of the Edwards Centre for Complex Pain of the Montreal Children's Hospital are supported by unrestricted grants from the Montreal Children's Hospital Foundation and from the Louise and Alan Edwards Foundation. We would also like to acknowledge the efforts of Émilie Groulx-Boivin from McGill University's Faculty of Medicine in helping structure and edit this review.

\section{Disclosure}

The authors report no conflicts of interest in this work.

\section{References}

1. Rametta SC, Fridinger SE, Gonzalez AK, et al. Analyzing 2589 child neurology telehealth encounters necessitated by the COVID-19 pandemic. Neurology. 2020;95(9):e1257-e1266. doi:10.1212/ WNL.0000000000010010

2. Carter CW, Herrero CP, Bloom DA, Karamitopoulos M, Castañeda PG. Early experience with virtual pediatric orthopedics in New York CityPearls for incorporating telemedicine into your practice. Bull Hosp Jt Dis. 2020;78(4):236-242.

3. Chen Y, Kathirithamby DR, Li J, Candelario-Velazquez C, Bloomfield A, Ambrose AF. Telemedicine in the coronavirus disease 2019 pandemic: a pediatric rehabilitation perspective. Am J Phys Med Rehabil. 2021;100(4):321-326. doi:10.1097/phm.0000000000001698

4. World health Organization. Telemedicine: opportunities and developments in member states. Report on the second global survey on eHealth. World Health Organization; 2010.

5. Tomines A. Pediatric telehealth: approaches by specialty and implications for general pediatric care. Adv Pediatr. 2019;66:55-85. doi:10.1016/j.yapd.2019.04.005

6. Killackey T, Noel M, Birnie KA, et al. COVID-19 pandemic impact and response in Canadian pediatric chronic pain care: a national survey of medical directors and pain professionals. Can J Pain. 2021;5 (1):139-150. doi:10.1080/24740527.2021.1931069

7. Perez J, Niburski K, Stoopler M, Ingelmo P. Telehealth and chronic pain management from rapid adaptation to long-term implementation in pain medicine: a narrative review. Pain Rep. 2021;6(1):e912. doi:10.1097/PR9.0000000000000912

8. Rabatin AE, Lynch ME, Severson MC, Brandenburg JE, Driscoll SW. Pediatric telerehabilitation medicine: making your virtual visits efficient, effective and fun. J Pediatr Rehabil Med. 2020;13(3):355-370. doi: $10.3233 /$ prm-200748
9. Buvik A, Bugge E, Knutsen G, Småbrekke A, Wilsgaard T. Quality of care for remote orthopaedic consultations using telemedicine: a randomised controlled trial. BMC Health Serv Res. 2016;16(1):1-11. doi:10.1186/s12913-016-1717-7

10. Buvik A, Bergmo TS, Bugge E, Smaabrekke A, Wilsgaard T, Olsen JA. Cost-effectiveness of telemedicine in remote orthopedic consultations: randomized controlled trial. J Med Internet Res. 2019;21(2):e11330. doi:10.2196/11330

11. Orlando JF, Beard M, Kumar S, Borsci S. Systematic review of patient and caregivers' satisfaction with telehealth videoconferencing as a mode of service delivery in managing patients' health. PLoS One. 2019;14(8):e0221848. doi:10.1371/journal.pone.0221848

12. Kruse CS, Krowski N, Rodriguez B, Tran L, Vela J, Brooks M. Telehealth and patient satisfaction: a systematic review and narrative analysis. BMJ Open. 2017;7(8):e016242. doi:10.1136/ bmjopen-2017-016242

13. Ruggiero MS. Common musculoskeletal complaints seen in pediatric primary care. In: Fast Facts Handbook for Pediatric Primary Care: A Guide for Nurse Practitioners and Physician Assistants. 2020:133.

14. Operating Procedures for Pediatric Telehealth. American Telemedicine Association; 2021. Available from: https://www. americantelemed.org/resources/operating-procedures-for-pedia tric-telehealth/. Accessed October 1, 2021.

15. International PMM. Virtual or Video-pGALS (V-pGALS). Pediatric musculoskeletal matters international. Available from: http://www.pmmonline.org/doctor/approach-to-clinical-assess ment/examination/v-pgals. Accessed March 4, 2021.

16. Pooni R, Ronis T, Lee T. Telemedicine use by pediatric rheumatologists during the COVID-19 pandemic. Pediatr Rheumatol Online J. 2021;19(1):93. doi:10.1186/s12969-021-00565-7

17. Noutsios $\mathrm{CD}$, Boisvert-Plante V, Laberge E, Perez J, Ingelmo P. The telemedicine-based pediatric examination of the back and lower limbs: a narrative review. J Pain Res. 2021;Volume 14:2959-2979. doi:10.2147/JPR.S329173

18. Laskowski ER, Johnson SE, Shelerud RA, et al. The telemedicine musculoskeletal examination. Mayo Clinic Proceedings. 2020;95 (8):1715-1731. doi:10.1016/j.mayocp.2020.05.026

19. Verduzco-Gutierrez M, Bean AC, Tenforde AS, Tapia RN, Silver JK. How to conduct an outpatient telemedicine rehabilitation or prehabilitation visit. $P M \& R$. 2020;12(7):714-720. doi:10.1002/ pmrj. 12380

20. Tanaka MJ, Oh LS, Martin SD, Berkson EM. Telemedicine in the era of COVID-19: the virtual orthopaedic examination. $J$ Bone Joint Surg Am. 2020;102(12):e57-e57. doi:10.2106/JBJS.20. 00609

21. Abel KC, Baldwin K, Chuo J, et al. Can telemedicine be used for adolescent postoperative knee arthroscopy follow-up? JBJS $J$ Orthopaed Physician Assistants. 2017;5(4):e26. doi:10.2106/ JBJS.JOPA.17.00014

22. Koong DP, Lee J, Cheng TL, Little DG. Validity and reliability of smartphone inclinometer applications for measurement of elbow range of motion in paediatric patients. $J$ Children's Orthopaed. 2020;14(5):488-494. doi:10.1302/1863-2548.14.200123

23. Atanda A, Shah SA. Virtual musculoskeletal examination using telemedicine. In: Telemedicine in Orthopedic Surgery and Sports Medicine. Springer; 2021:81-84.

24. Ullucci PA, Tudini F, Moran MF. Reliability of smartphone inclinometry to measure upper cervical range of motion. $J$ Sport Rehabil. 2019;28(1). doi:10.1123/jsr.2018-0048

25. Stenneberg MS, Busstra H, Eskes M, et al. Concurrent validity and interrater reliability of a new smartphone application to assess $3 \mathrm{D}$ active cervical range of motion in patients with neck pain. Musculoskeletal Sci Pract. 2018;34:59-65. doi:10.1016/j. msksp.2017.12.006 
26. Quek J, Brauer SG, Treleaven J, Pua Y-H, Mentiplay B, Clark RA. Validity and intra-rater reliability of an android phone application to measure cervical range-of-motion. J Neuroeng Rehabil. 2014;11(1):1-6. doi:10.1186/1743-0003-11-65

27. Chang K-V, Wu W-T, Chen M-C, Chiu Y-C, Han D-S, Chen -CC. Smartphone application with virtual reality goggles for the reliable and valid measurement of active craniocervical range of motion. Diagnostics. 2019;9(3):71. doi:10.3390/diagnostics90 30071

28. Guidetti L, Placentino U, Baldari C. Reliability and criterion validity of the smartphone inclinometer application to quantify cervical spine mobility. Clin Spine Surg. 2017;30(10):E1359E1366. doi:10.1097/BSD.0000000000000364

29. Rodríguez-Sanz J, Carrasco-Uribarren A, Cabanillas-Barea S, et al. Validity and reliability of two smartphone applications to measure the lower and upper cervical spine range of motion in subjects with chronic cervical pain. J Back Musculoskelet Rehabil. 2019;32(4):619-627. doi:10.3233/BMR-181260

30. Palsson T, Christensen S, Thomsen M, Hirata R. Assessment of range and quality of neck movement using a smartphone-based application. Musculoskeletal Sci Pract. 2019;41:64-69. doi:10.1016/j.msksp.2019.01.002

31. Pourahmadi MR, Bagheri R, Taghipour M, Takamjani IE, Sarrafzadeh J, Mohseni-Bandpei MA. A new iPhone application for measuring active craniocervical range of motion in patients with non-specific neck pain: a reliability and validity study. Spine J. 2018;18(3):447-457. doi:10.1016/j.spinee.2017.08.229

32. Monreal C, Luinstra L, Larkins L, May J. Validity and intrarater reliability using a smartphone clinometer application to measure active cervical range of motion including rotation measurements in supine. J Sport Rehabil. 2020;30(4):680-684. doi:10.1123/ jsr.2019-0422

33. Ghorbani F, Kamyab M, Azadinia F. Smartphone applications as a suitable alternative to CROM device and inclinometers in assessing the cervical range of motion in patients with nonspecific neck pain. $J$ Chiropr Med. 2020;19(1):38-48. doi:10.1016/j.jcm.2019.10.004

34. Mani S, Sharma S, Singh DK. Concurrent validity and reliability of telerehabilitation-based physiotherapy assessment of cervical spine in adults with non-specific neck pain. $J$ Telemed Telecare. 2019;27:1357633X19861802.

35. Mani S, Sharma S, Omar B, Ahmad K, Muniandy Y, Singh DKA. Quantitative measurements of forward head posture in a clinical settings: a technical feasibility study. Eur J Physiother. 2017;19 (3):119-123. doi:10.1080/21679169.2017.1296888

36. Satin AM, Lieberman IH. The virtual spine examination: telemedicine in the era of COVID-19 and beyond. Global Spine J. 2020;2192568220947744. doi:10.1177/2192568220947744

37. Iyer S, Shafi K, Lovecchio F, et al. The spine physical examination using telemedicine: strategies and best practices. Global Spine $j$. 2020;2192568220944129. doi: 10.1177/2192568220944129

38. Yoon JW, Welch RL, Alamin T, et al. Remote virtual spinal evaluation in the era of COVID-19. Int J Spine Surg. 2020;14 (3):433-440. doi:10.14444/7057

39. Robblee $\mathrm{J}$ Conducting a telemedicine neurologic examination. American Headache Society; 2020. Available from: https://amer icanheadachesociety.org/news/telemedicine-neurologic-examina tion/. Accessed February 23, 2021.

40. Jarman NF, Brooks T, James CR, et al. Deep neck flexor endurance in the adolescent and young adult: normative data and associated attributes. $P M \& R$. 2017;9(10):969-975. doi:10.1016/ j.pmrj.2017.02.002

41. Lauridsen HH, Hestbaek L. Development of the young spine questionnaire. BMC Musculoskelet Disord. 2013;14(1):1-9. doi:10.1186/1471-2474-14-185
42. Jansen T, Gathen M, Touet A, et al. [Spine examination during COVID-19 pandemic via video consultation] Telemedizinische Wirbelsäulenuntersuchung während der COVID-19-Pandemie. Z Orthop Unfall. 2021;159(2):193-201. doi:10.1055/a-1283-7160

43. Yedlinsky NT, Peebles RL. Telemedicine management of musculoskeletal issues. Am Fam Physician. 2021;103(3):147-154.

44. Cabrera-Martos I, Ortiz-Rubio A, Torres-Sánchez I, López-López L, Rodríguez-Torres J, Carmen Valenza M. Agreement between face-to-face and tele-assessment of upper limb functioning in patients with Parkinson disease. Pm\&r. 2019;11(6):590-596. doi:10.1002/pmrj.12001

45. Russo RR, Burn MB, Ismaily SK, et al. Is digital photography an accurate and precise method for measuring range of motion of the shoulder and elbow. J Orthop Sci. 2017. 23:310-315

46. Mejia-Hernandez K, Chang A, Eardley-Harris N, Jaarsma R, Gill TK, McLean JM. Smartphone applications for the evaluation of pathologic shoulder range of motion and shoulder scores-a comparative study. JSES Open Access. 2018;2(1):109-114. doi:10.1016/j.jses.2017.10.001

47. Pinnamaneni S, Lamplot JD, Rodeo SA, et al. The virtual shoulder physical exam. HSS J. 2021;17(1):59-64. doi:10.1177/ 1556331620975033

48. Lamplot JD, Pinnamaneni S, Swensen-Buza S, et al. The virtual shoulder and knee physical examination. Orthopaedic J Sports Med. 2020;8(10):2325967120962869. doi:10.1177/2325967120 962869

49. Edmonds EW, Bastrom TP, Roocroft JH, Calandra-Young VA, Pennock AT. The Pediatric/Adolescent Shoulder Survey (PASS): a reliable youth questionnaire with discriminant validity and responsiveness to change. Orthop J Sports Med. 2017;5 (3):2325967117698466. doi:10.1177/2325967117698466

50. Quatman-Yates CC, Gupta R, Paterno MV, Schmitt LC, Quatman $\mathrm{CE}$, Ittenbach RF. Internal consistency and validity of the quickDASH instrument for upper extremity injuries in older children. J Pediatr Orthopaed. 2013;33(8):838-842. doi:10.10 97/BPO.0b013e3182a00688

51. Goldstein Y, Schermann H, Dolkart O, et al. Video examination via the smartphone: a reliable tool for shoulder function assessment using the constant score. J Orthopaed Sci. 2019;24(5):812816. doi:10.1016/j.jos.2018.12.023

52. Sprowls GR, Brown JC, Robin BN. The shoulder telehealth assessment tool in transition to distance orthopedics. Arthrosc Tech. 2020;9(11):e1673-e1681. doi:10.1016/j.eats.2020.07.008

53. Sabbagh R, Shah N, Jenkins S, et al. The COVID-19 pandemic and follow-up for shoulder surgery: the impact of a shift toward telemedicine on validated patient-reported outcomes. $J$ Telemed Telecare. 2021:1357633×21990997. doi:10.1177/1357633×21990 997.

54. Bradley KE, Cook C, Reinke EK, et al. Comparison of the accuracy of telehealth examination versus clinical examination in the detection of shoulder pathology. J Shoulder Elbow Surg. 2021;30(5):1042-1052. doi:10.1016/j.jse.2020.08.016

55. Mani S, Sharma S, Omar B, Paungmali A, Joseph L. Validity and reliability of internet-based physiotherapy assessment for musculoskeletal disorders: a systematic review. J Telemed Telecare. 2017;23(3):379-391. doi:10.1177/1357633X16642369

56. Cottrell MA, O'Leary SP, Swete-Kelly P, et al. Agreement between telehealth and in-person assessment of patients with chronic musculoskeletal conditions presenting to an advancedpractice physiotherapy screening clinic. Musculoskeletal Sci Pract. 2018;38:99-105. doi:10.1016/j.msksp.2018.09.014

57. Rabin A, Dolkart O, Kazum E, et al. Shoulder assessment by smartphone: a valid alternative for times of social distancing. Arch Orthop Trauma Surg. 2021;1-7. doi:10.1007/s00402-02103762-x 
58. Kane LT, Thakar O, Jamgochian G, et al. The role of telehealth as a platform for postoperative visits following rotator cuff repair: a prospective, randomized controlled trial. J Shoulder Elbow Surg. 2020;29(4):775-783. doi:10.1016/j.jse.2019.12.004

59. Crawford AM, Lightsey HM, Xiong GX, Striano BM, Schoenfeld AJ, Simpson AK. Telemedicine visits generate accurate surgical plans across orthopaedic subspecialties. Arch Orthop Trauma Surg. 2021;1-8. doi:10.1007/s00402-021-03903-2

60. Lawton CD, Swensen-Buza S, Awender JF, et al. The elbow physical examination for telemedicine encounters. HSS J. 2021;17(1):65-69. doi:10.1177/1556331620975040

61. Smits-Engelsman B, Klerks M, Kirby A. Beighton score: a valid measure for generalized hypermobility in children. $J$ Pediatr. 2011;158(1):119-123.e4. doi:10.1016/j.jpeds.2010.07.021

62. Dent Jr PA, Wilke B, Terkonda S, Luther I, Shi GG. Validation of teleconference-based goniometry for measuring elbow joint range of motion. Cureus. 2020;12(2). doi:10.7759/cureus.6925

63. Meislin MA, Wagner ER, Shin AY. A comparison of elbow range of motion measurements: smartphone-based digital photography versus goniometric measurements. J Hand Surg Am. 2016;41 (4):510-515. e1. doi:10.1016/j.jhsa.2016.01.006

64. Keijsers R, Zwerus EL, van Lith DRM, et al. Validity and reliability of elbow range of motion measurements using digital photographs, movies, and a goniometry smartphone application. $J$ Sports Med. 2018;2018:7906875. doi:10.1155/2018/7906875

65. Shields MN, Vaichinger AM, O'Driscoll SW. Smartphone "Selfies"-A reliable and accurate tool for measuring elbow range of motion. Shoulder Elbow. 2019;13:1758573219869206.

66. Lin NCJ, Hayward KS, D'Cruz K, Thompson E, Li X, Lannin NA. Validity and reliability of a smartphone inclinometer app for measuring passive upper limb range of motion in a stroke population. Disabil Rehabil. 2020;42(22):3243-3249. doi:10.1080/ 09638288.2019.1585972

67. Behnoush B, Tavakoli N, Bazmi E, et al. Smartphone and universal goniometer for measurement of elbow joint motions: a comparative study. Asian J Sports Med. 2016;7(2). doi:10.5812/ asjsm.30668.

68. Santos C, Pauchard N, Guilloteau A. Reliability assessment of measuring active wrist pronation and supination range of motion with a smartphone. Hand Surg Rehabil. 2017;36(5):338-345. doi:10.1016/j.hansur.2017.06.005

69. Lee JC. A study on the reliability and validity of measuring the range of motion of the elbow joint using a smartphone application. Int J Internet, Broadcast Commun. 2018;10(3):65-72.

70. Reid S, Egan B. The validity and reliability of DrGoniometer, a smartphone application, for measuring forearm supination. $J$ Hand Ther. 2019;32(1):110-117. doi:10.1016/j.jht.2018.03.003

71. M PG, Subramanyan H, Merlin JJ. A study to analyse the reliability and validity of the smartphone goniometer application (G-PRO) by measuring the elbow joint range of motion. Indian J Public Health Res Dev. 2020;11(3). doi:10.37506/ijphrd.v11i3.824

72. Alford SL. Remote self-measurement of wrist range of motion performed on normal wrists by a minimally trained individual using the iPhone level application only demonstrated good reliability in measuring wrist flexion and extension. $J$ Hand Ther. 2020. doi:10.1016/j.jht.2020.05.001

73. Modest J, Clair B, DeMasi R, et al. Self-measured wrist range of motion by wrist-injured and wrist-healthy study participants using a built-in iPhone feature as compared with a universal goniometer. $J$ Hand Ther. 2019;32(4):507-514. doi:10.1016/j. jht.2018.03.004

74. Dubrovsky AS, Mok E, Lau SY, Al Humaidan M. Point tenderness at 1 of 5 locations and limited elbow extension identify significant injury in children with acute elbow trauma: a study of diagnostic accuracy. Am J Emerg Med. 2015;33(2):229-233. doi:10.1016/j.ajem.2014.11.028
75. Magra M, Caine D, Maffulli N. A review of epidemiology of paediatric elbow injuries in sports. Sports Med. 2007;37(8):717735. doi:10.2165/00007256-200737080-00005

76. Wahezi SE, Duarte RA, Yerra S, et al. Telemedicine during COVID-19 and beyond: a practical guide and best practices multidisciplinary approach for the orthopedic and neurologic pain physical examination. Pain Physician. 2020;23(4s):S205s238.

77. Van Nest DS, Ilyas AM, Rivlin M. Telemedicine evaluation and techniques in hand surgery. J Hand Surg Global Online. 2020;2 (4):240-245. doi:10.1016/j.jhsg.2020.05.006

78. Grandizio LC, Foster BK, Klena JC. Telemedicine in hand and upper-extremity surgery. J Hand Surg Am. 2020;45(3):239-242. doi:10.1016/j.jhsa.2019.09.007

79. Ge M, Chen J, Zhu Z, Shi P, Yin L, Xia L. Wrist ROM measurements using smartphone photography: reliability and validity. Hand Surg Rehabil. 2020;39(4):261-264. doi:10.1016/j. hansur.2020.02.004

80. Trehan SK, Rancy SK, Johnsen PH, Hillstrom HJ, Lee SK, Wolfe SW. At home photography-based method for measuring wrist range of motion. J Wrist Surg. 2017;6(04):280-284. doi:10.1055/s-0037-1599830

81. Wagner ER, Conti Mica M, Shin AY. Smartphone photography utilized to measure wrist range of motion. J Hand Surg. 2017;43 (2):187-192. doi:10.1177/1753193417729140

82. Scott KL, Skotak CM, Renfree KJ. Remote assessment of wrist range of motion: inter- and intra-observer agreement of provider estimation and direct measurement with photographs and tracings. J Hand Surg Am. 2019;44(11):954-965. doi:10.1016/j. jhsa.2019.05.017

83. Zhao JZ, Blazar PE, Mora AN, Earp BE. Range of motion measurements of the fingers via smartphone photography. Hand. 2019;1558944718820955. doi:10.1177/1558944718820955

84. Chen J, Xian Zhang A, Jia Qian S, Jing Wang Y. Measurement of finger joint motion after flexor tendon repair: smartphone photography compared with traditional goniometry. J Hand Surg. 2021;1753193421991062. doi:10.1177/1753193421991062

85. Meals CG, Saunders RJ, Desale S, Means KR Jr. Viability of hand and wrist photogoniometry. Hand. 2018;13(3):301-304. doi:10.1177/1558944717702471

86. Lendner N, Wells E, Lavi I, Kwok YY, Ho P-C, Wollstein R. Utility of the iPhone 4 gyroscope application in the measurement of wrist motion. Hand. 2019;14(3):352-356. doi:10.1177/ 1558944717730604

87. Pourahmadi MR, Ebrahimi Takamjani I, Sarrafzadeh J, et al. Reliability and concurrent validity of a new iPhone ${ }^{\circledR}$ goniometric application for measuring active wrist range of motion: a crosssectional study in asymptomatic subjects. J Anat. 2017;230 (3):484-495. doi:10.1111/joa. 12568

88. Lee HH, St. Louis K, Fowler JR. Accuracy and reliability of visual inspection and smartphone applications for measuring finger range of motion. Orthopedics. 2018;41(2):e217-e221. doi:10.3928/01477447-20180103-02

89. Wright-Chisem J, Trehan S. The hand and wrist examination for video telehealth encounters. HSS j. 2021;17(1):70-74. doi:10.1177/1556331620975341

90. Wainberg MC, Jurisson ML, Johnson SE, Brault JS. The telemedicine hand examination. Am J Phys Med Rehabil. 2020;99 (10):883. doi:10.1097/phm.0000000000001555

91. Welle K, Täger S, Hackenberg RK, et al. [Examining the hand in the video consultation] Die Untersuchung der Hand in der Videosprechstunde. Z Orthop Unfall. 2021;159(2):202-208. doi:10.1055/a-1304-3593

92. Fetter-Zarzeka A, Joseph MM. Hand and fingertip injuries in children. Pediatr Emerg Care. 2002;18(5):341-345. doi:10.1097/00006565-200210000-00003 
93. Shah SS, Rochette LM, Smith GA. Epidemiology of pediatric hand injuries presenting to United States emergency departments, 1990 to 2009. J Trauma Acute Care Surg. 2012;72(6):1688-1694. doi:10.1097/TA.0b013e31824a4c5b

94. Berger C, Holzach P, Matter P. [Skier's thumb injury in the child] Die Skidaumenverletzung beim Kind. Helv Chir Acta. 1994;60 (4):615-621.

95. Tofte JN, Anthony CA, Polgreen PM, et al. Postoperative care via smartphone following carpal tunnel release. $J$ Telemed Telecare. 2020;26(4):223-231. doi:10.1177/1357633X18807606

96. Worboys T, Brassington M, Ward EC, Cornwell PL. Delivering occupational therapy hand assessment and treatment sessions via telehealth. J Telemed Telecare. 2018;24(3):185-192. doi:10.1177/ 1357633X17691861

97. Mehta SP, Kendall KM, Reasor CM. Virtual assessments of knee and wrist joint range motion have comparable reliability with faceto-face assessments. Musculoskeletal Care. 2020;19:208-216.

98. van Rijn SF, Zwerus EL, Koenraadt KL, Jacobs WC, van den Bekerom MP, Eygendaal D. The reliability and validity of goniometric elbow measurements in adults: a systematic review of the literature. Shoulder Elbow. 2018;10(4):274-284. doi:10.1177/ 1758573218774326
99. Scott Kruse C, Karem P, Shifflett K, Vegi L, Ravi K, Brooks M. Evaluating barriers to adopting telemedicine worldwide: a systematic review. $J$ Telemed Telecare. 2018;24(1):4-12. doi:10.1177/1357633X16674087

100. Davis LE, Harnar J, LaChey-Barbee LA, Pirio RS, Fraser A, King MK. Using teleneurology to deliver chronic neurologic care to rural veterans: analysis of the first 1100 patient visits. Telemed e-Health. 2019;25(4):274-278. doi:10.1089/ tmj.2018.0067

101. Nolen L, Mejia NI. Inequities in neurology amplified by the COVID-19 pandemic. Nat Rev Neurol. 2021;17(2):67-68. doi:10.1038/s41582-020-00452-x

102. Lester B, Halbrecht J, Levy IM, Gaudinez R. Press test" for office diagnosis of triangular fibrocartilage complex tears of the wrist. Ann Plast Surg. 1995;35(1):41-45. doi:10.1097/00000637199507000-00009

\section{Publish your work in this journal}

The Journal of Pain Research is an international, peer reviewed, open access, online journal that welcomes laboratory and clinical findings in the fields of pain research and the prevention and management of pain. Original research, reviews, symposium reports, hypothesis formation and commentaries are all considered for publication. The manuscript management system is completely online and includes a very quick and fair peer-review system, which is all easy to use. Visit http:// www.dovepress.com/testimonials.php to read real quotes from published authors. 